use. It is, however, encouraging that occasional users seemed to move towards abstinence rather than daily use. Other features of the results could also be regarded as encouraging-for example, even among those individuals who were taking opiates again at six months the amounts used were lower than at admission to treatment: the number of high dose users had dropped from 21 to three. Moreover, fewer subjects were taking opiates by injection: their number had dropped from 30 who were injecting regularly at admission to only 17 who had injected at any time during the six months after discharge. As the admission of the subjects studied coincided with the beginning of the campaign against the acquired immune deficiency syndrome this reduction in injecting may have been due in some part to a greater awareness of the hazards of injecting. Other studies have suggested that addicts are capable of modifying their drug taking behaviour to take account of such information. ${ }^{25}$ This result also suggests the value of further research into the possibilities of building "harm reduction" packages into treatment programmes aimed at problem drug takers.

The data presented in this paper were collected as part of a research project funded by the Department of Health and Social Security. We would also like to thank Dr Philip Connell for his support during the early stages of the project and Dr John Strang for his helpful comments on a draft of the paper.

\section{References}

1 Litman GK, Eiser JR, Taylor C. Dependence, relapse and extinction: a theoretical critique and a behavioural examination. 7 Clin Psychol 1979;35:192-9.

2 Hunt WA, Barnett CW, Branch LG. Relapse rates in addiction programs. $\mathcal{f}$ Clin Psychol 1971;27:455-6

3 Marlatt GA, Gordon JR. Determinants of relapse: implications for the maintenance of behavio change. In: Davidson PO, Davidson SM, eds. Behavioral medicine: changing health lifestyles. New York: Brunner-Mazel, 1980.
4 Litman GK, Eiser JR, Rawson NSB, Oppenheim AN. Differences in relapse precipitants and coping behaviour between alcohol relapsers and survivors. Behav Res Ther 1979;17:89-94

5 Litman GK. Relapse in alcoholism. In: Edwards G, Grant M, eds. Alcohol treatment in transition. London: Croom Helm, 1980.

6 Marlatt GA. Craving for alcohol, loss of control and relapse: a cognitive-behavioral analysis. In Nathan PE, Marlatt GA, Loberg T, eds. Alcoholism: new directions in behavioral research and treatment. New York: Plenum, 1978.

7 Marlatt GA, Parks GA. Self-management of addictive disorders. In: Kardy P, Kanfer FH, eds. Self-management and behavior change. Elmsford, New York: Pergamon Press, 1982:443-88.

8 Chaney EF, Roszell DK, Cummings C. Relapse in opiate addicts: a behavioural analysis. Addic Behav 1983;7:291-9.

9 McAuliffe WE. A test of Wikler's theory of relapse: the frequincy of relapse due to conditioned withdrawal sickness. Int 7 Addict 1982;17:19.33.

$10 \mathrm{O}$ 'Brien CP, Ternes JW. Conditioning as a cause of relapse in narcotic addiction. In: Schecter A Alksne $\mathrm{H}, \mathrm{Kaufman} \mathrm{E}$, eds. Coatesville-fefferson conference on addiction. New York: Pergamon Press, 1979.

11 Stimmel B, Rotkopf E, Cohen MJ. Parameters defining the ability to remain abstinent after detoxification from methadone: a six year study. In: Schecter A, Alksne H, Kaufman E, eds. National drug abuse conference. Critical concerns in the field of drug abuse. New York, Basle: Marcel Dekker, 1978:190-2.

12 Gossop M. Living with drugs. London: Maurice Temple Smith, 1982.

13 Stimson GV, Oppenheimer E, Thorley A. Seven-year follow-up of heroin addicts: drug use and outcome. Br Med f 1978;i:1190.

14 Stimson GV, Oppenheimer E. Heroin addiction treatment and control in Biritain. London: Tavistock Publications, 1982.

15 Gossop $M$, Johns A, Green L. Opiate withdrawal: inpatient versus outpatient programmes and preferred versus random assignment to treatment. $\mathrm{Br}$ Med f 1986;293: 103-4

16 Johns A, Gossop M. Prescribing methadone for the opiate addict: a problem of dosage conversion. Drug Alcohol Depend 1985;16:61-6.

17 Medical Working Group on Drug Dependence. Guidelines of good clinical practice in the treatment of drug misuse. London:-Department of Health and Social Security, 1984.

18 Banks A, Waller TAN. Drug addiction on polydrug abuse: the role of the general practitioner. London Library and Information Service, Institute for the Study of Drug Dependence, 1983.

19 Litman GK. Alcoholism survival: the prevention of relapse. In: Miller W, Heather N, eds. Treating addictive behavior. New York: Plenum, 1986.

20 Schur E. Narcotic addiction in Britain and America. The impact of public policy. London: Tavistock Publications, 1963.

II tinstein S. The narcotics dilemma: who is listening to what? Im.7 A d dict 1966;1:1-6.

22 Thorley A. Longitudinal studies of drug dependence. In: Griffith E, Busch C, eds. Drug problem in Britain. A review of ten years. London: Academic Press, 1981.

23 Brown BS. Addicts and aftercare. Beverley Hills, London: Sage, 1979.

24 Marlatt GA. Relapse prevention: theoretical rationale and overview of the model. In: Marlatt GA Gordon JR, eds. Relapse prevention. New York: Guilford Press, 1985.

25 Strang J, Heathcote S, Watson P. Habit moderation in injecting drug addicts. Health Trends (in press).

(Accepted 18 March 1987)

\title{
Successful treatment of acute mountain sickness with dexamethasone
}

\author{
GIANMARIO FERRAZZINI， MARCO MAGGIORINI， SUSI KRIEMLER， PETER BÄRTSCH, \\ OSWALD OELZ
}

\begin{abstract}
A double blind, randomised, placebo controlled trial of treatment with dexamethasone for acute mountain sickness was performed in the Capanna "Regina Margherita" at an altitude of $4559 \mathrm{~m}$ in the Alps Valais. After 12-16 hours of treatment $(8 \mathrm{mg}$ dexamethasone initially, followed by $4 \mathrm{mg}$ every six hours) the mean acute mountain sickness score decreased significantly from 5.4 to 1.3 , and eight of 17 patients became totally asymptomatic. Mean arterial oxygen saturation rose from $75 \cdot 5 \%$ to $82 \cdot 0 \%$, and there
\end{abstract}

Department of Medicine, University Hospital, CH-8091 Zürich, Switzerland GIANMARIO FERRAZZINI, MD, house officer in medicine

SUSI KRIEMLER, medical student

OSWALD OELZ, MD, lecturer in medicine

Ospedale la Carita, Locarno, Switzerland

MARCO MAGGIORINI, MD, house officer in medicine

Department of Medicine, University of Berne, Switzerland

PETER BÄRTSCH, MD, senior house officer in medicine

Correspondence to: Dr Oelz. was a small increase in standard spirometric measurements. In the placebo group none of these variables changed significantly.

It is concluded that dexamethasone may be used as emergency treatment for acute mountain sickness to facilitate safe descent to a lower altitude.

\section{Introduction}

The early stages of acute mountain sickness are characterised by peripheral oedema, headache, lassitude, insomnia, and nausea. These may progress to vomiting, ataxia, severe lassitude, breathlessness, and frank pulmonary or cerebral oedema. ${ }^{12}$ The syndrome occurs in subjects who rapidly ascend to altitudes of $3000 \mathrm{~m}$ or more, taking from a few hours to a few days to develop. The incidence of acute mountain sickness in the Alps correlates with the speed of ascent and the absolute altitude. ${ }^{3}$

Acute mountain sickness may be prevented in most cases by graded ascent and prophylaxis with acetazolamide. ${ }^{1+5}$ Recently, dexamethasone has been shown to prevent the symptoms of acute mountain sickness in an altitude chamber, when its beneficial effects were thought to be due to a reduction in brain oedema.

The only effective remedy for patients with fully developed acute 
BRITISH MEDICAL JOURNAL VOLUME $294 \quad 30$ MAY 1987

mountain sickness is descent or evacuation to a lower altitude or, if this is impossible, treatment with oxygen.$^{78}$ Occasionally, descent or evacuation may be prevented by weather or avalanche conditions and oxygen equipment is not available. In such circumstances a simple drug regimen for acute mountain sickness is desirable.

Previous studies have shown a high incidence of acute mountain sickness, in addition to pulmonary and cerebral oedema, in some of the high Alpine huts in Switzerland and Italy. ${ }^{389}$ The highest of them, the Capanna "Regina Margherita," is located at an altitude of $4559 \mathrm{~m}$ on the Punta Gnifetti summit of Monte Rosa in the Valais sickness score, to $1 \cdot 3(2 \cdot 0)(\mathrm{p}<0 \cdot 001)$. In eight patients treated with dexamethasone all symptoms and signs of acute mountain sickness resolved (score 0 ), whereas in two the score fell by only one point (figure). In addition, the incidence of certain symptoms - namely, headache, nausea, and vomiting-was significantly reduced by dexamethasone $(p<0.001)$. In contrast, the mean acute mountain sickness score in the placebo group did not change significantly $(4 \cdot 4(2 \cdot 2))$. In eight patients the score improved by 1-4 points, in two it remained the same, and in another eight it deteriorated by 1-4 points (figure). The change in the acute mountain sickness score was $4 \cdot 1$ in the dexamethasone group and 0.4 in the placebo group, a difference of $3 \cdot 7$ (confidence interval $=-5 \cdot 3$ to $-2 \cdot 2$ ).

Mean (SD) \% changes in responses of patients to tests before and after treatment with placebo or dexamethasone

\begin{tabular}{lccr}
\hline & Placebo & Dexamethasone & Mean difference (95\% confidence interval) \\
\hline Arterial oxygen saturation & $1 \cdot 6(8 \cdot 3)(\mathrm{n}=18)$ & $6 \cdot 5(8 \cdot 0)<0 \cdot 01(\mathrm{n}=17)$ & $4 \cdot 9(-10 \cdot 5$ to \\
Forced vital capacity & $2 \cdot 1(5 \cdot 5)(\mathrm{n}=18)$ & $4 \cdot 8(5 \cdot 8)<0 \cdot 01(\mathrm{n}=15)$ & $-6 \cdot 9(-10 \cdot 9 \cdot$ to $-2 \cdot 8)$ \\
Forced expiratory volume in one second & $2 \cdot 2(9 \cdot 3)(\mathrm{n}=18)$ & $5 \cdot 8(4 \cdot 9)<0 \cdot 001(\mathrm{n}=15)$ & $-8 \cdot 0(-13 \cdot 4$ to $-2 \cdot 6)$ \\
Minute ventilation & $7 \cdot 8(29 \cdot 1)(\mathrm{n}=17)$ & $3 \cdot 1(24 \cdot 0)(\mathrm{n}=15)$ & $4 \cdot 7(-14 \cdot 7$ to $24 \cdot 0)$ \\
\hline
\end{tabular}

Alps. Symptoms and signs of acute mountain sickness develop in as many as half of the mountaineers there because of the rapid gain in altitude when they ascend to $2800 \mathrm{~m}$ or $3200 \mathrm{~m}$ in a cable car and then proceed to the summit by a technically easy climb over glaciers. This provided us with an ideal opportunity to study the effectiveness of dexamethasone in the treatment of acute mountain sickness.

\section{Subjects and methods}

Climbers arriving at the Capanna "Regina Margherita" at noon or later who planned to stay over night received a posted message to determine whether they had any symptoms of acute mountain sickness. If they had symptoms they were invited to participate in the study. After giving informed consent, volunteers had to rest for at least two hours before they were evaluated with a questionnaire. ${ }^{1}$ The presence of the symptoms listed was scored as follows: one point for mild headache, nausea, dizziness, shortness of breath and insomnia and two points for severe headache (not relieved by acetaminophen $500 \mathrm{mg}$ ) and for vomiting. Responses were checked with one of the investigators. Subjects then underwent a clinical examination for tachypnoea (two points), facial or peripheral oedema (one location one point, two or more locations two points), ataxia (heel to toe walking test and Romberg test two points), and pulmonary rales (discreet one point, pronounced two points).

Patients with three or more points were selected for the drug trial. Three patients with frank high altitude pulmonary or cerebral oedema, or both, were not included in the study but evacuated by helicopter. Subjects were weighed and after 10 minutes' rest in a supine position arterial oxygen saturation was measured with an ear oxymeter (Biox II, Bioxymetry Technology). Resting minute ventilation, forced vital capacity, and forced expiratory volume in one second were then measured with a Volugraph 2000 (Mijnhardt, Holland). Retinal photography was performed as described, and the width of the arteries and veins was measured. ${ }^{6}$ Subsequently, 35 patients were randomly assigned to receive dexamethasone by mouth $(8 \mathrm{mg}$ initially and another $4 \mathrm{mg}$ after six and 12 hours) or identical placebo. After 12-16 hours all procedures were repeated.

Statistical analysis-Data are presented as means (SD) or as differences between the treatment groups before and after treatment. The $\chi^{2}$ test was used to evaluate the acute mountain sickness score. Patients with a score of $\leqslant 2$ were considered to be cured and normal as one or two slight signs or symptoms occur in more than half of all mountaineers at this altitude. The paired $t$ test was used, and confidence intervals are given in the results.

\section{Results}

The two groups were comparable in age, history of acute mountain sickness, and speed of ascent. There were five women and 13 men in the placebo group and two women and $15 \mathrm{men}$ in the dexamethasone group. The mean acute mountain sickness scores for the groups before treatment were comparable: placebo group $4 \cdot 8(1 \cdot 0)$, dexamethasone group $5 \cdot 4(1 \cdot 7)$. After 12-16 hours of treatment dexamethasone reduced the symptoms and signs of acute mountain sickness noticeably, as assessed by the acute mountain
Weight did not change significantly in the placebo group $(-0.23(1.03) \%)$ and dropped by $0.75(0.65) \%$ in patients treated with dexamethasone $(p<0 \cdot 01$, confidence interval of mean differences $=-0 \cdot 2$ to $1 \cdot 24)$. There were no significant changes in pulse rate or blood pressure in either group, but arterial oxygen saturation increased from $75 \cdot 5(7 \cdot 8) \%$ to $82.0(8 \cdot 0) \%$ in patients treated with dexamethasone $(p<0.01)$ with no significant change in the placebo group $(76 \cdot 2(6 \cdot 3) \%$ to $77 \cdot 8(8 \cdot 2) \%$. Forced vital capacity and forced expiratory volume in one second increased slightly but significantly in climbers treated with dexamethasone but not in those who received placebo (table). There were no significant changes in resting minute ventilation or the diameter of the retinal arteries and veins.
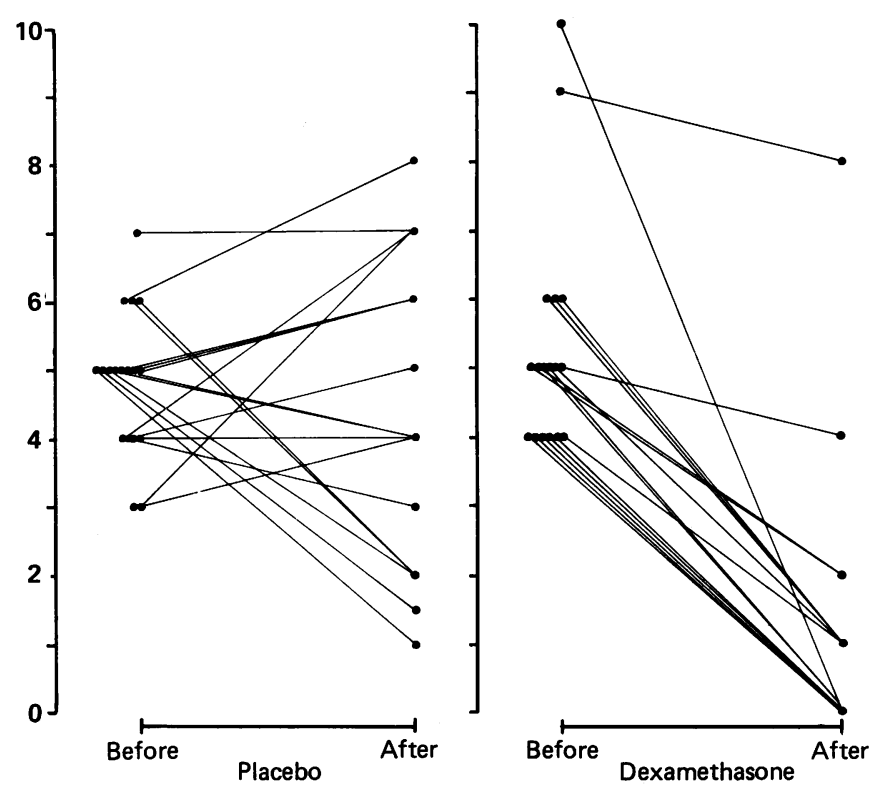

Acute mountain sickness score of mountaineers before and after 12-16 hours of treatment with placebo or dexamethasone.

\section{Discussion}

In this study dexamethasone had a noticeable effect on the signs and symptoms of moderate to severe acute mountain sickness. We must emphasise, however, that patients with high altitude pulmonary or cerebral oedema were not included in the study. While most mountaineers treated with dexamethasone improved noticeably and descended without any help, several patients treated with placebo had to be helped because of ataxia, severe malaise, and headache. The clinical course of those in the placebo group also illustrates 
the unpredictable and variable course of acute mountain sickness.

This study has shown that dexamethasone may be used not only prophylactically, as shown by Johnson $e t a l,{ }^{6}$ but also to treat fully established acute mountain sickness. Johnson et al observed a reduction in the diameter of retinal arteries and suggested that dexamethasone reduced cerebral oedema, and though we did not find a significant reduction in the diameter of retinal vessels, the pronounced reduction in cerebral symptoms, such as headache, suggests that such an effect is probable.

The reduction in symptoms in the dexamethasone group coincided with an increase in arterial oxygen saturation and a small improvement in spirometric variables. As the minute ventilation did not change the improvement in arterial oxygen saturation might have been due to a reduction in postulated interstitial pulmonary oedema. The weight loss in patients who received dexamethasone supports this theory and might be the result of a more general mobilisation of oedema fluid accumulated during the development of acute mountain sickness.

Though the potential long term effects of dexamethasone may be neglected during short term administration, this treatment should be reserved for emergencies to facilitate safe descent. Patients who improve with treatment should be discouraged from ascending further. ${ }^{10}$ " Severe acute mountain sickness may be avoided in most cases by slow ascent and by taking rest days when early symptoms occur or, if these progress, by descent. ${ }^{712}$
We thank the Club Alpino Italiano Sezione Varallo in the Capanna "Regina Margherita" and the Centre for Biostatistics at the University of Zürich for advice. This study was supported by a grant from the EMDO Stiftung.

\section{References}

1 Hackett PH, Rennie D, Levine HD. The incidence, importance, and prophylaxis of acute mountain sickness. Lancet 1976;ii:1149-54.

2 Hackett PH, Rennie D. Rales, peripheral edema, retinal hemorrhage and acute mountain sickness. Am $\mathcal{F}$ Med 1979;67:214-8.

3 Maggiorini M, Buehler B, Walter M, Oelz O. Inzidenz und Erscheinungsformen der akuten Bergkrankheit in den Schweizer Hochalpen. Schweiz Med Wochenschr 1986;116 (suppl 20):24.

4 Forwand SA, Landowne M, Follansbee JN, Mansen JE. Effect of acetazolamide on acute mountain sickness. $N$ Engl f Med 1968;279:839-45.

5 Birmingham Medical Research Expeditionary Society. Acetazolamide in the control of acute mountain sickness. Lancet 1981;ii: 180-3.

6 Johnson TS, Rock PB, Fulco CS, Trad LA, Spark RF, Maher JT. Prevention of acute mountain sickness by dexamethasone. N Engl I Med 1984;310:683-6.

7 Houston CS. Going high. The story of man and altitude. New York: American Alpine Club, 1980

8 Mosso A. Life of man in the high Alps. London: T Fisher Unwin, 1898.

9 Hochstrasser J, Nanzer A, Oelz O. Das Höhenlungenödem in den Schweizer Alpen. Beobachtungen über Inzidenz, Klinik und Verlauf bei 50 Patienten der Jahre 1980-1984. Schweiz Med Wochenschr 1986;116:866-73.

10 Ferreira P, Grundy P. Dexamethasone in the treatment of acute mountain sickness. N Engl f Med 1985;312:1390.

11 Shlim DR. Treatment of acute mountain sickness. $N$ Engl f Med 1985;313:891

12 Hackett PH. Mountain sickness. Prevention, recognition and treatment. New York: American Alpine Club, 1980.

(Accepted 16 January 1987)

\section{SHORT REPORTS}

\section{Intraregional variation in treatment of end stage renal failure}

Though much has been written on the international and national variations of acceptance and treatment rates for end stage renal failure, ${ }^{12}$ more local data are not routinely available because the European Dialysis and Transplant Association Registry does not collect information by the area of residence. We report the results of a survey carried out by one region.

\section{Patients, methods, and results}

In 1984 information was obtained on the mode of treatment and area of residence of all patients living in the North West Thames region who were admitted to treatment for end stage renal failure during 1983 and were still alive and having treatment at 31 December 1983. Information was collected from the units within the region and from units within neighbouring regions. The district specific acceptance and treatment rates adjusted for age and sex were calculated by using the 1983 final population estimates published by the Office of Populations, Censuses, and Surveys. The distance in kilometres (as the crow flies) of all electoral wards was weighted by population to give the average distance for each health authority from the nearest unit. Spearman rank correlation tests were carried out to investigate the relation between the distance from the provision of service and treatment and acceptance rates.

The district specific acceptance rate ranged from 8 to 73 per million population and there was a similar differential pattern for the district specific treatment rate, from 134 to 357 per million population (figure). Significant rank correlations were found between the distance from a renal unit and the age/sex adjusted acceptance $(r=0.68, p<0.01)$ and treatment $(r=0.89, p<0.002)$ rates for end stage renal failure.

\section{Comment}

Treatment for end stage renal failure is traditionally provided in teaching hospitals in Britain. This may result in patients having to travel considerable distances. The distance as the crow flies was used as the measure of service access; evidence suggests there is little to choose between it and alternative measures. ${ }^{3}$ The survey did not include the private sector; nevertheless, few British residents receive treatment for end stage renal failure outside the National Health Service. Possibly there is a higher incidence of the disease in West Indian and Asian people. ${ }^{4}$

The numbers involved in the acceptance rate calculation are small; the pattern is very similar, however, for the rate of patients alive with end stage

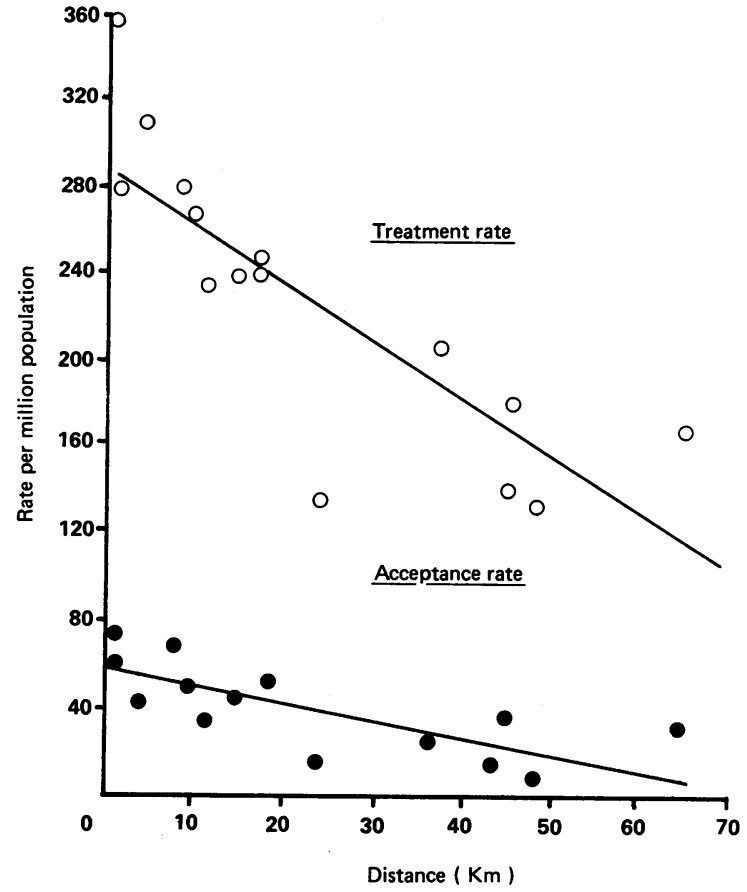

Treatment and acceptance rates for end stage renal failure by district health authority with distance from nearest renal unit.

renal failure per million population on 31 December 1983. This suggests similar differential acceptance rates over a period of time. Our results suggest that the further one lives from a dialysis centre the less likelihood there is of receiving lifesaving treatment. These findings have not been noted before.

One reason for these differentials may be different referral practices by general practitioners and hospital consultants. ${ }^{5}$ Possibly the further hospital consultants and general practitioners are from a dialysis centre the less likely they will be to have up to date information about the methods of treatment, such as the use of continuous ambulatory peritoneal dialysis and the move 